\title{
EL INDÍGENA Y SU PROCESO INDEPENDENTISTA: HUAROCHIRÍ DURANTE EL GOBIERNO DE SAN MARTÍN, VISIBILIZANDO NUESTRA MICROHISTORIA
}

\author{
THE INDIGENOUS AND THEIR INDEPENDENCE PROCESS: HUAROCHIRÍ DURING \\ THE GOVERNMENT OF SAN MARTÍN, MAKING OUR MICROHISTORY VISIBLE
}

\author{
DOI: https://doi.org/10.47190/rcsaw.v2i3.6 \\ Recibido: 03/01/22 \\ Aceptado: 01/02/22 \\ Erik Lionel Felix Asencio \\ https://orcid.org/0000-0003-1786-9215
de Educación Enrique Guzmán y Valle
}

\section{RESUMEN}

La nueva documentación sobre la independencia del Perú, en conjunto con las memorias de los propios participantes de este acontecimiento histórico, han permitido que se pueda construir y describir en la presente investigación la gran y valerosa participación del indígena huarochirano por la emancipación durante finales de 1820, con la formación de la primera partida guerrillera al mando de Quispe Ninavilca y José Manrique, hasta el 20 de septiembre de 1822, día en la que San Martín dejó el país. Se describen los enfrentamos constantes de las guerrillas con las fuerzas realistas, incluso con el propio virrey La Serna, fuera y dentro de su territorio como en San Mateo y otros puntos estratégicos de la zona, así como los movimientos constantes de los indígenas y la política intransigente del libertador llevando a la provincia a notables perjuicios

Palabras clave: Guerrillas; Huarochirí en la independencia; Lucha indígena e independencia del Perú.

\begin{abstract}
Abstract: The new documentation on the independence of Peru, together with the memories of the participants themselves of this historical event, have allowed that the great and courageous participation of the Huarochirano indigenous for the emancipation during the end of 1820 can be constructed and described in the present investigation., with the formation of the first guerrilla party under the command of Quispe Ninavilca and Jose Manrique, until September 20,1822, the day on which San Martín left the country. The constant confrontations of the guerrillas with the royalist forces are described, including with Viceroy La Serna himself, outside and within his territory such as in San Mateo and other strategic points in the area, as well as the constant movements of the indigenous people and politics. uncompromising of the liberator, leading the province to considerable damage.
\end{abstract}

Keywords: Guerrillas; Huarochirí in independence; Indigenous struggle and independence of Peru. 


\section{Introducción}

Todo indica que la participación del indígena huarochirano a favor de la emancipación inició poco antes de la llegada de San Martín al Perú, esto considerando las memorias que escribió Francisco de Vidal, quien como es sabido, fue enviado antes del arribo del bonaerense con la misión de formar guerrillas a favor de la independencia e ir ganando terreno en una guerra que aún no iniciaba en tierras incaicas. Castro (2018) nos aclara aún más el panorama sobre esta interrogante, tomando a Ninavilca, curaca de Huarochirí, como prueba de la participación indígena de dicho territorio antes del arribo del argentino, al ser pues este uno de los iniciadores de la formación de montoneras en suelo peruano: Los documentos de 1820 y las informaciones de años posteriores, según el prólogo de la doctora Temple, «adveran en forma incontrovertible, la existencia de las guerrillas patriotas encabezadas entre otros por Vidal, Acuña, Ninavilca, Huavique, Zárate, Quiroz, y muchos otros caudillos de partidas, antes de la llegada de San Martín; o su inmediata creación y rápido incremento al arribo de la Expedición Libertadora a las costas peruanas». Igualmente asegura, párrafos antes, que Francisco Javier Mariátegui, al tratar de las guerrillas, destacó «su constitución en la etapa previa a la llegada de la Expedición Libertadora» (p. 57).

Las noticias sobre el inminente arribo del bonaerense al Perú habían circulado rápidamente por la sierra peruana, motivando inmediatamente al indígena a formarse y alistarse en pro del gran levantamiento contra la opresión hispana. Como bien menciona la anterior cita, Ninavilca habría formado su partida guerrillera antes de siquiera el arribo de San Martín a Paracas, es decir, a finales de agosto o a muy principios días de septiembre de 1820. El gran historiador Germán Leguía ratifica lo dicho al afirmar que cuando arribó el ejercito patriota a la costa peruana, Ninavilca ya había organizado su partida "no muy numerosa, pues apenas si, en su pleno desarrollo, contó con ciento ochenta y un hombres voluntarios, reunidos desde Santa Eulalia hasta la Oroya" (Leguía, 1972, t. 3, p. 318), con los cuales mostraría, y a pesar de ser unos cuantos en pie de lucha, Huarochirí, iniciando así la provincia desde muy temprano su participación en la alargada guerra.

Asimismo, debemos tener en cuenta que la formación de las guerrilleras huarochiranas por parte de Ninavilca no fueron las únicas, una mención honrosa merece José Manrique, personaje destacable que había participado en el levantamiento del Cusco (1814) siendo colaborador activo de Mateo Pumacahua, y que, pese a la dura derrota, había mantenido intacto sus sueños de liberar al país. Manrique, luego de este importante suceso en la capital incaica, "anduvo errante por provincias cercanas al Cuzco, hasta que, en 1820, al conocerse el desembarco de San Martín, organizó con Quispe Ninavilca y otros las guerrillas de Huarochirí" (Castro, 2018, p. 57).

Otro factor que no se puede dejar de lado al referirnos al inicio de la participación de las guerrillas huarochiranas, es pues la condición geográfica de la provincia, sin duda, clave para el perfecto desarrollo de la guerra de guerrillas, sus estrechos caminos y ventajosas quebradas, como la de San Mateo, convertían al territorio en zona perfecta para ataques sorpresas desde las alturas, donde los galgueros contaban con una perfecta visibilidad sin ser además blanco visible para el armamento realista, el lanzamiento de sus proyectiles desde las escabrosas alturas, será pues una enorme ventaja en medio de las grandes carencias.

Una geografía llana para los indios rebeldes, hubiera sido seguramente un factor influyente al momento de considerar cualquier levantamiento, las armas de guerra indígena habrían quedado cuasi obsoletas en territorio plano, obligándolos a realizar nuevas estrategias de guerra, o en el peor de los casos, y en contra de sus voluntades, desistir de cualquier intento de sublevación, esto último desde luego, no de manera masiva, pero sí en una cantidad de mayor consideración a la que hacen referencia los documentos, los cuales nos muestran una realidad innegable de cómo algunos pobladores optaban por huir de la zona, así como también, su contraparte, es decir, la valentía de quienes se posicionaron al lado de la emancipación.

Existía, por tanto, una estrecha relación entre la geografía de los indios sublevados, y las armas utilizadas para la guerra, siendo las galgas el armamento más usado y efectivo por los naturales, aquel instrumento de guerra tradicional que había perdurado a través de los siglos y que se mantendrá como principal arma para la provincia hasta los últimos encuentros con los peninsulares. Huarochirí entonces, como territorio de guerra, se había convertido en una especie de fortín, ventajosa para los guerrilleros y devastadora para los ejércitos 
realistas, convirtiéndose San Mateo o el propio Carampoma, en puntos clave para la dirección de las demás zonas aledañas de la sierra, esto según lo cuenta el propio Álvarez de Arenales (como se citó en Leguía, 1972, t. 3):

Los cuarteles principales o centros de acción y dirección eran (...) las quebradas de Canta, hasta Copacabana: de San Mateo y de Huarochirí"; (...) radicase en San Mateo, como punto intermediario o céntrico entre las tres quebradas, y en el que una relativa equidistancia facilitaba la expedición de órdenes inmediatas y la explosión de embestidas y movimientos reglados, convergentes, armónicos, simultáneos (p. 327)

Asimismo, es preciso mencionar que esta guerra por la independencia, tomó parcialmente preparados a los huarochiranos en tácticas guerrilleras, y más aún, en cómo utilizar su territorio para causar los mayores males posibles. 1536, año del levantamiento de Manco Inca, 1750 y 1783, habían sido los años de mayor revuelo, donde los huarochiranos colaboraron también con los levantamientos indígenas como la de Felipe Velasco Inga, causando gran zozobra a la capital del virreinato, desde donde se tuvo que enviar un numeroso ejército para apagar la llama del levantamiento.

\section{Guerrillas huarochiranas durante el inicio de la Ilegada de San Martín}

Luego del desembarco de San Martín en Paracas, y la inmediata conferencia de Miraflores, el argentino como es sabido envió a Álvarez de Arenales, de "virtudes espartanas", rumbo a la sierra con la consigna de levantar a los pueblos a favor de la emancipación, conseguir soldados y bloquear la capital del virreinato, teniendo claro que para lograr dicho propósito era indispensable contar con el apoyo de las provincias que cercaban la capital, más aún, a sabiendas que eran estas provincias las que principalmente proveían a la ciudad de alimentos y materia prima, como Yauli, conocida como "la nueva Potosí" por su abundante riqueza en plata, y Huarochirí, desde donde se recolectaba uno de los principales embarques de papa, frutas y el propio hielo para la conservación de los alimentos:

Obligar á los españoles á abandonar este punto era de necesidad y ese plan, no se lograba sino poniendo á Lima en asedio, y para ello conveía que los peruanos levantáramos tropas que nos ayudasen. Colaboradores tuvimos; fueron de los peruanos levantáramos tropas que nos ayudasen. Colaboradores tuvimos; fueron de los primeros, Ninavilca, Huavique y otros vecinos de Huarochirí y de Canta (F. J. Mariátegui, 1869, p. 41).

El plan de Arenales consistía atravesar la sierra central del Perú, pasando por Huamanga, Huancavelica, Huancayo, Tarma, Jauja y Cerro de Paco para luego retornar a la capital. Así, como se puede apreciar, la estrategia emprendida por el patriota no comprendía la ruta hacia Huarochirí, siendo ello probablemente uno de los motivos por la que los indígenas de la provincia no se sumaron, en ese primer momento, en masa a la campaña independentista, no obstante, esto no quiere decir que estuvieron desinformados de los movimientos de Arenales y que no realizaron ningún esfuerzo en pro de la emancipación, por el contrario, lo que provocó la presencia del argentino en las inmediaciones de la provincia fue un gran revuelo inicial, donde las primeras guerrillas formadas antes de la llegada de San Martín se consolidaron y ganaron más presencia en el resto de la región.

La rápida formación y levantamiento en los pueblos será, sin embargo, una gran amenaza para la política en mente de los criollos, el fragor de aquella sublevación necesitaba según el propio San Martín, "orden", pues de lo contrario, fracasarían irremediablemente en el intento separatista. La historiografía moderna ha catalogado este hecho como un intento del libertador por frenar o controlar a las masas, temeroso de un cambio social que perjudique los intereses de la aristocracia. Por lo que finalmente, y como es sabido, la clase dirigente del levantamiento se impuso y logró alcanzar y afianzar sus objetivos, puesto que, "las clases inferiores no ganarían nada con la independencia. Libertad y Constitución, términos oídos por primera vez, no les significaba nada [para el indígena]" (Montoya, 2002, p. 70).

Enseguida del 6 de diciembre de 1820, día en la que Arenales obtuvo la victoria en Cerro de Pasco enfrentándose a las tropas realistas al mando de O'Reylli, los pobladores huarochiranos se preparaban para recibir a las fuerzas recolectadas por el primer guerrillero del Perú, Francisco de Vidal, quien había escapado junto a los suyos de la capital luego de que el virrey Pezuela ordenara al General Rodil reclutar a los esclavos de los alrededores de la ciudad para sumárseles a su ejército, por lo que San Martín inmediatamente ordenó a Vidal sacar rumbo a la Revista de Ciencias Sociales Aplicadas W Wynarroque| pág. 57 
sierra a todos aquellos que se habían incorporado al ejército patriota, tomando así Vidal la ruta hacia Huarochirí como lo narra en sus memorias:

Emprendí mi marcha por los pueblos altos de Chancay (...) y como mi objeto era no ser sentido por los españoles, continué mi marcha por caminos escusados (...) Llegamos al pueblo de Collata del Distrito de Santa Olaya [Huarochirí], en la noche tomamos el camino por donde se conducía la nieve a esta capital, a la una o dos de la mañana, asaltamos la tropa que guardaba la caballada, y fueron todos tomado por mí los que remití a la sierra por el camino que había traído (Francisco de Vidal, 1972, p. 340).

De lo narrado se puede sostener que, en tiempos tan tempranos a la guerra, Huarochirí era aún tierra en la que primaban los destacamentos hispanos, pero en la que también se contaba ya con algunos "caminos escudados". Asimismo, se da un esbozo de cómo serían los constantes ataques de los guerrilleros, de manera rápida e inesperada, debiendo destacar además que estos primeros enfrentamientos iban de la mano con las acciones de Ninavilca, quien tenía una misión igual de difícil, la cual consistía en sumar en masa a sus vecinos al levantamiento: "Mientras yo hacía estas correrías el cacique Ninavilca hacía jurar la independencia en todos los pueblos de su provincia Huarochirí" (Francisco de Vidal, 1972, p.340).

Ninavilca por supuesto, con la credibilidad que gozaba en los pueblos huarochiranos, logró conformar para inicios de 1821 una partida guerrillera mucho más numerosa a la que se formó la primera vez, con los cuales, inmediatamente después de organizarse, y en plena primera campaña de Arenales en la sierra, tuvo que sostener su primer enfrentamiento contra los soldados realistas, ello debido a las acciones Coronel Francisco Bermúdez y del Mayor Aldao, quienes luego de la partida de Arenales a la sierra, se habían quedado en Ica con una pequeña guarnición, la misma que fue aumentando considerablemente al enlistarse indios y esclavos de las distintas partes aledañas a capital, sin embargo, y como es de suponerse, esta partida en formación no contaba con armas eficientes para defenderse de cualquier ataque realista, por lo que una vez informados que el enemigo llegaba por el norte y sur, decidieron marcharse a la sierra, llegando así la guerra a la provincia.

Por el lado realista, poco antes del primer enfrentamiento sostenido en Huarochirí, el General Ricafort, que había recibido órdenes de marchar de Arequipa hacia la capital, se enteró estando en Nazca del movimiento de Bermúdez y Aldao, optando así por perseguir y acabar con la reciente fuerza emergente. Hubo enfrentamientos, entre otros puntos, en Huamanga y Cangallo, siendo los españoles quienes cruelmente arrasen con poblaciones enteras. Ya para el retorno del general español, este tuvo que enfrentarse a las fuerzas de Paula de Otero en Huancayo, quien había logrado organizar un contingente guerrillero junto a Bermúdez y Aldao, "la lucha pronto habría de degenerar en una horrenda carnicería. Como en Huamanga y Cangallo, las tropas de línea mataban y mataban sin dar cuartel a ninguno que se ponían al alcance de sus armas" (Roel, 1971, p. 111).

Ante la inminente derrota, Bermúdez rápidamente optó por replegarse hacia la ciudad de Huaura, mientras que las fuerzas que acompañaban a Aldao y Otero marcharon rumbo a Tarma con los pocos hombres que habían sobrevivido al horrendo ataque español. Para Paz Soldán (1868), Ricafort había cometido un grave error al no perseguir y acabar a la moribunda fuerza indígena, quienes rápidamente lograron reconstruirse, por el contrario, lo que hizo el general hispano fue retornar a la capital tomando la ruta huarochirana, convirtiéndose así la provincia en el nuevo foco de batalla entre ambos bandos.

Inmediatamente los patriotas, conociendo las grandes ventajas geográficas que ofrecía el territorio de la provincia, decidieron enviar refuerzos desde Tarma, así lo hace saber Manuel Rosas en su carta a Otero el 10 diciembre de 1820: “amigo mío invité V. á esos Tarmeños para que obren con actividad por la Quebrada de San Mateo, con la confianza de que nos abrazaremos antes de 20 días en el sepulcro de la tiranía" (como se citó en Nueva Colección Documental de la Independencia del Perú, 2018a, p. 260). Había confianza del lado patriota, los enemigos cansados se enfrentarían a frescos guerrilleros de la zona en la peligrosa quebrada de San Mateo.

Los coloniales, sin embrago, contando aún con el control de las zonas aledañas a la capital, como lo es Huarochirí, estuvieron al tanto de los movimientos indígenas, por lo que decidieron posicionar unos 300 soldados en Matucana, reforzándolos además con cañones y con una retaguardia en Surco, teniendo como finalidad, no solo acabar con las guerrillas que se aproximaban a la provincia, sino además, aislar a 
las tropas de Arenales en la sierra, puesto que "encerrada entre varios fuegos; aislada en el centro del Perú; incomunicada con San Martín; perdida, sin refugio ni auxilio, en las interioridades y escabrosidades de la sierra (...) [estaría] expuesto a ser destruido sin remisión, o a rendirse miserablemente después" (Leguía, 1972, t. 3, p. 32).

No obstante, ni las posiciones tomadas por los realistas, ni sus poderosos armamentos, pudieron cortar con el entusiasmo inicial de las partidas huarochiranas, entusiasmo que a su vez era llenado por las proclamas de la época, las cuales hablaban de una guerra muy próxima a acabar, casi asegurando que no pasaría de 1820, cabe preguntarse entonces si aquello fue un cruel engaño, o en contraparte, una confianza desmedida, lo cierto es que las promesas de un rápido triunfo claramente motivaron a los huarochiranos, como a sus vecinos, a sumarse en masa a la causa emancipadora. La siguiente es una proclama para tomarla como referencia de lo mencionado, fechada del 13 diciembre 1820, fue pues repartida en primera instancia a los pueblos de Acobamba, Tapo y Huasahuasi, pero que más tarde llegaron a todo el territorio peruano:

Nuestras valerosas tropas de la Patria han triunfado ya gloriosamente en todas las Provincias del Perú, y por su generoso esfuerzo vamos recuperando los preciosos derechos de nuestra libertad, de que por más de trescientos años nos había despojado el feroz despotismo. Solo resta que se rinda la capital de Lima para concluir el fin de la campaña. Nuestro invicto Capitán General Don José de San Martin la ataca personalmente por mar y tierra: al mismo fin se dirige por Canta con todo el empeño nuestro General Arenales: y queriendo yo tener parte en las seguras glorias de la Patria marcho el sábado 16 del corriente por la quebrada de San Mateo a derrotar una pequeña división enemiga para que por todas partes se franquee la entrada a Lima (como se citó en Nueva Colección Documental de la Independencia del Perú, 2018, p. 272).

Así, con la confianza de derrotar al enemigo en tierras huarochiranas, la siguiente misiva que envía Otero a Arenales el 14 de diciembre de 1820, no hace más que confirmar la numerosa participación del indígena huarochirano en la guerra por la independencia, "en efecto, casi todos los vecinos se me han presentado gustosos, (...) a reunirse con todas las partidas que están situadas en varios puntos y que reunidas puede constar de mil hombres" (como se citó en Nueva Colección Documental de la Independencia del Perú, 2018a, p. 281). En esta misma carta, sin embargo, se refleja también el mal equipamiento militar patriota, puesto que solo la mitad contaban con fusiles, añadiendo para peores males que, según Otero, todo armamento "que quedó [con los huarochiranos] esta inútil y necesita lo menos dos meses para ponerlo expedito" (como se citó en Nueva Colección Documental de la Independencia del Perú, 2018a, p. 281).

Finalmente, las tropas guerrilleras reconstituidas Tarma marcharon el 18 de diciembre con todas las carencias posibles rumbo a San Mateo, donde se unieron a los huarochiranos que presentaban las mismas grandes dificultades. No obstante, Otero, cayendo en contradicción, luego de haber referido la gran adición huarochirana a la causa patriota, hizo reflotar pues su recelo para con los indígenas sublevados, como también, su intento por controlar a las masas, puesto que prohibió que a las partidas de la provincia recibieran armamento para el enfrentamiento que se avecinaba, así lo hace saber en su orden del 17 de diciembre de 1820:

No permita $U$. que esos vecinos tengan armas (...) Haciendo esto comprensivo a los Pueblos de ese contorno para que presenten los fusiles que hayan recogido; y al primero que encuentre $U$. que no lo haga cumplido escarmentarlo para ejemplo de los demás (como se citó en Nueva Colección Documental de la Independencia del Perú, 2018a, p. 107).

Con las nuevas disposiciones de Otero, la situación se complicaba aún más para los naturales, no obstante, el plan siguió siento el mismo, enviar los refuerzos a Huarochirí, siendo Acuña el encargado de marchar al mando de las guerrillas tarmeñas, y quién también reciba las órdenes de replegarse hacia Yauli si el número de realistas superaban a los suyos, sin embargo, nada salió como lo previsto, Acuña no logró contener a las masas huarochiranas ni sus aliados, quienes producto de su entusiasmo marcharon hasta San Pedro de Mama (cerca a Chosica), arriesgándose a una derrota casi segura en territorio favorable para los hispanos. Esta acción desde luego fue reprendida por Arenales, quien en carta a Otero expresa su malestar de la siguiente manera: "mucho siento, que las tropas de esa provincia se hayan avanzado hasta cerca de San Pedro Mama, hacia a la Capital de Lima; Revista de Ciencias Sociales Aplicadas Waynarroque pág. 59 
pues no es cordura, y me temo fundadamente, que padezcan un contraste" (como se citó en Nueva Colección Documental de la Independencia del Perú, 2018a, p. 315).

Lo oportuno para Arenales era que dichos guerrilleros se mantuviesen en los alrededores de San Mateo, sin aproximarse a la capital, y sin entablar enfrentamiento directo, manifestando además eufóricamente en la misma carta su descontento con Acuña, quien según sus dichos, haciendo caso omiso a las órdenes que se le había dado, se lanzó a "provocar a los enemigos hasta cerca de San Mateo con una gente sin disciplina, sin dirección, y sin sostén formal, que más bien se puede llamar montonera que tropa, y contra las enemigas, que son muy veteranas" (como se citó en Nueva Colección Documental de la Independencia del Perú, 2018a, p. 316).

Desde la narración oficialista se podría decir que el plan patriota no consistía en realizar una avanzada temeraria hasta los puntos controlados por los españoles, puesto que significaría perder el enfrentamiento, y con ello, el entusiasmo indígena, sepultando así quizá desde el inicio el masivo levantamiento. Sin embargo, la posición crítica de lo narrado toma a Otero como un personaje que veía en el movimiento de los huarochiranos, y en el de Acuña, un peligro inminente para la lucha criolla, donde el mayor temor era que la lucha indígena se terminara por separar de los lineamientos de la clase dominante.

Lo cierto es que las órdenes del general patriota habían sido claras, moverse hasta la quebrada de San Mateo, llamar la atención hispana para que Arenales pueda llegar a Canta sin mayor sobresalto y finalmente reunirse con San Martín para la toma de la capital, o en caso contrario, y si las fuerzas se encontraban en peligro de ser aniquiladas, retornar a Yauli. Así lo hace saber el propio Otero en su contestación a Arenales, por lo que se mostraba sorprendido del accionar guerrillero.

Por el otro lado, Ricafort realizaba su avance de manera incontenible hacia provincia, lo que obligó a Otero y Aldao, luego de la arriesgada maniobra de los huarochiranos, a volver sobre sus pasos rumbo a Jauja en busca de refuerzos para aguantar al enemigo. Así, al pisar Ricafort suelo huarochirano, las órdenes para encararlo serían las mismas, es decir, no entablar batalla directa, sin embargo, al igual que en diciembre del año anterior, tanto Acuña como Aldao, que había. logrado reponer y engrosar sus filas en Jauja, no pudieron controlar a los guerrilleros, siendo las consecuencias terriblemente negativas para los patriotas. Según lo narrado por Otero, en carta a San Martín el 7 de febrero de 1821, Acuña y los suyos habían realizado un tímido repliegue que terminó en una cruenta batalla en la que fueron derrotados:

Se me han presentado veinte y un hombres de la partida de don Antonio Acuña asegurándome después de haber atacado al enemigo en las inmediaciones de Santa Inés y quitándole quinientas vacas dos mil corderos y algunas mulas se replegaron con un desorden extraordinario que ocasionó el no haber salvado el ganado ni podido reunirse (...) quedado por esta razón la Provincia de Huarochirí sin partida que incomode al enemigo, y atendiendo a las súplicas que han venido a hacerme los Paisanos hemos acordado que el Teniente de Guerrillas don Pablo Jeremías pase con sesenta hombres montados que tiene a ocupar esos puntos con sus correspondientes instrucciones de hostilizar al enemigo y hacerles la guerra en los términos que nos tiene ordenado (como se citó en Nueva Colección Documental de la Independencia del Perú, 2018a, p. 452).

Con las cosas favorables para los hispanos, Ricafort finalmente logró entrar a Lima "lleno de orgullo, exagerando sus triunfos y habiendo circulado en la sierra varias proclamas arrogantes, que empezaba renegando y concluía amenazando" (José Arenales, 1982 , p. 8). No obstante, si bien las tropas realistas salieron relativamente airosas en su enfrentamiento con las guerrillas de la sierra, el bando patriota había logrado sumar a pueblos enteros a favor de la causa, donde los huarochiranos dieron sus primeras demostraciones de valentía y entrega por sus ideales.

Asimismo, se puede decir que el caos realista a finales de 1821, producto de los cuestionamientos a Pezuela al no lograr avances militares, de alguna manera agilizaron el alzamiento de la sierra, el motín de Aznapuquio, y la toma de mandato por parte de La Serna, no hizo más que evidenciar el caos e ingobernabilidad en la que se vivía del lado colonial, aprovechando este tiempo los patriotas para formar al Ejército Regular del Perú, en donde las Ilamadas las montoneras se convertirán en paridas guerrillas, teniendo como sus guías más próximos a los propios curacas. 
No obstante, durante la formación de estos numerosos ejércitos indígenas, un temeroso San Martín va a poner algunas trabas y casi nulo interés por ver concretizado este proyecto, el latente peligro que veía para las clases dominantes del país, y con ello, la caída de las negociaciones con la aristocracia limeña, hizo que este mirara de costado las mencionadas formaciones, poniendo pleno interés en consolidar su control sobre el norte peruano, uniendo lazos con los grandes terratenientes de la zona, como con el Márquez de Torre Tagle, así lo hace saber José Arenales (1822) en sus memorias: "el General San Marín aprovechó los momentos en organizar tropas y numerosos recursos en las provincias de norte, y consolidar en ellas su posición política" (p. 2).

Se podría decir entonces que la formación de estos ejércitos se dio gracias a Felix Aldao, quien logró obtener un gran poder de convocatoria sobre los indios, y a quien, además, el propio San Martín temía por su fervor y ansias de batallar de manera decisiva contra el enemigo. Es conocido que Aldao anteriormente había incumplido con las órdenes de San Martín, pues confiando en el poder de los indios alzados, decidió enfrentar a los realistas en la ya mencionada desastrosa batalla de Huancayo, lo que obligó al libertador reprender y aclararle al guerrillero la principal misión de las partidas, los cuales, según sus planes, consistía nada más que en hostilizar a los realistas. Así las cosas, le dio libertad a Aldao para que conformase sus partidas, nombrándole además Teniente Coronel de estas, donde la caballería tomó el nombre de Granaderos del Perú, y la infantería, Leales del Perú.

Conociendo Aldao que muchas veces el nombre da importancia á, la cosa, escogió de entre su multitud 900 hombres, y organizándolos en lo posible les dio el nombre de batallón. Con el mismo objeto separó una compañía para artillería (...). Así mismo formó un escuadrón lo mejor que pudo, unos tenían monturas de una clase, otros de otra, varios llevaban solo sables, estas tercerolas, aquellos lanzas, y los demás fusil, de modo que daba risa ver tan original caballería. Aldao con un entusiasmo digno de la causa que defendía solo pensaba en aumentar su división dándole la apariencia de tropa de línea (Paz Soldán, 1868, pp. 132-133).

En esta gran formación de partidas guerrilleras, los indígenas Huarochiranos desde luego formaron el suyo al mando de Quispe Ninavilca, la organización de estas se había hecho a manera de cuerpos de línea, siendo la huarochirana la tercera:
En el mismo intervalo el General en Gefe se apresuró á plantear las partidas de guerrillas en las quebradas inmediatas á Lima. [Una de ellas, la del] cacique Ninavilca, [quienes] (...) aparecieron hostilizando las cercanías de Lima, y aterrando al enemigo con repetidas azañas y estratagemas (José Arenales, 1822, p. 2).

Con lo referenciado, lo que se puede sostener es que los patriotas nunca tuvieron problemas en cuanto a recursos humanos, voluntarios abundaban en cada lugar recorrido. Sin embargo, hay algo que no podemos dejar de mencionar, y es el choque que se originó entre los guerrilleros y mandos militares, Gamarra, por ejemplo, quien había asumido la jefatura de las fuerzas guerrilleras, no tardó en chocar con las "indisciplinas" de los indígenas, con su modus vivendi y su forma de batalla, pues simplemente, no iban en la misma línea que las prácticas militares profesionales, entonces, solo quedaba dos caminos, que los indígenas se acomodaran a las formas de sus mandos militares, o que ocurriese todo lo contrario, siendo esto último lo que realmente sucedió. Los campos de descanso patriota se transformaron así en un terreno de ambiente casi anárquico, en la que las jerarquías o mandos pasaban a segundo plano, no era extraño ver incluso en algunas oportunidades como el ímpetu de los guerrilleros se supeditaba a la autoridad de sus comandantes, de igual manera, los propios comandantes de provincia se revelaban contra sus superiores, siendo el propio Ninavilca quien confirmara los hechos: "Todos los Comandantes de partidas se ponen galones y no reconocen jefe superior que los mande" (como se citó en Nueva Colección Documental de la Independencia del Perú, 2018a, p. 28).

Un nuevo tiempo se avecinaba para la provincia debido a que dejará de ser controlada plenamente por los realistas, empezando así una nueva pugna entre ambos bandos por el control de la zona estratégica. A finales de 1820 e inicios de 1821, las tierras huarochiranas eran campos habitados por ambos bandos, por lo que no se podía arriesgar a mandar soldados del ejército patriota con armamentos y demás gastos hacia la provincia en mención. Riva Agüero y Francisco Javier Mariátegui, tuvieron por ejemplo una discusión al respecto, luego de que el batallón Numancia, que había sufrido varias restructuraciones, se pasara al lado patriota, la discusión giraba en torno a saber hacia dónde se les debía encomendar en su lucha, para Riva Agüero, el batallón debía marchar hacia la sierra en apoyo a las Revista de Ciencias Sociales Aplicadas Waynarroque| pág. 61 
fuerzas de Arenales, tomando como ruta y parada obligatoria la provincia de Huarochirí, cosa contraria opinaba F.J. Mariátegui, percatándose que la zona era aún insegura para enviar a tal destacamento:

eran grandes y terribles los riesgos á que los exponíamos, y por esto no lo admitimos, si lograba el batallón llegar á la sierra y salir de Huarochirí, era muy posible y casi seguro que sería batido por los que saliesen de Lima (F.J. Mariátegui, 1869, pp. 26-27).

F.J. Mariátegui, además, como varios otros criollos, consideraba a la capital como fortín realista, donde se encontraba el mayor poderío bélico y desde donde partían las fuerzas españolas a reforzar o aniquilar cualquier fuerza independentista, por lo que apoyaba el proyecto de San Martín de ocupar Lima. Sin embrago, otros tantos criticaban la decisión del libertador, puesto que veían a la capital como zona ganada y arruinada por el bloqueo, por lo que consideraban a la sierra como el lugar estratégicomilitar y de abastecimiento a ocupar de manera urgente. Finalmente, lo que se puede percibir entonces es que para F.J. Mariátegui, como lo destaca en sus memorias, Huarochirí era un territorio totalmente patriota, pero que, a la vez, se presentaba insegura para el ejército oficial a inicios de la guerra.

Asimismo, es preciso ratificar la importancia geográfica de San Mateo, que para esta nueva etapa de la guerra, pasó a ser la base para las guerrillas: "fijase para residencia del jefe y para cuartel general de montoneras, el pueblo de San Mateo (...) determinase una serie de cuarteles secundarios en las tres quebradas paralelas, contiguas a la capital" (Leguía, 1972, t. 4, p. 46).

\section{Guerrillas huarochiranas frente a los destacamentos de Monet y Valdez}

Desde el primer trimestre de 1821, los indígenas habían logrado cortar gran parte de los suministros que partían hacia la capital, sembrando así el caos y la desesperación en la ciudad, por lo que ya con la designación de La Serna como nuevo virrey, este "dispuso que Monet pasara a apaciguar la zona de Huarochirí y Yauyos, de donde debía llevar provisiones a la capital que estaba cada vez más escasa de víveres" (Roel, 1971, pp. 121-122). Sin embrago, no solamente ese era el objetivo, sino también como lo aclara Dellepiane (1977), el "de destruir el germen de libertad que Arenales había sembrado a su paso por esa región" (p. 88). Claro está, esto no ocurriría de manera pacífica, sino por el contrario, utilizarían todo tipo de arsenal de destrucción temiendo en cuanta que "quemar y arrasar pueblos enteros, fue siempre una diversión sencilla para los españoles: [por lo que] la historia mostrará un día la gran lista que han corrido tan ilustre suerte a manos de los dignos sucesores de Pizarro" (José Arenales, 1822, p. 29).

Se encuentra como continuación de las palabras de Arenales lo dicho por Germán Leguía, quien luego de describir la valerosa participación de la partida de Cayetano Quirós en su lucha contra las tropas hispanas en Santa Eulalia en marzo de 1821, describe lo siguiente: "la sorpresa de San Jerónimo, pueblecillo del distrito de Santa Eulalia, (...) donde (...) aniquiló un destacamento español respetable, que acababa de reducir a cenizas seis caseríos o aldeas de la zona circunvecina" (Leguía, 1972, t. 3, p. 325).

Así las cosas, sobre la marcha de Monet a Huarochirí y Yauyos, lo que de puede mencionar es que su empresa no fue para nada favorable a sus intereses, las partidas de ambas provincias le dieron tales batallas a los hispanos que perdieron gran cantidad de hombres y armamento, por lo que "a duras penas Monet pudo apoderarse de alimentos en la zona, pero no alcanzó su objetivo de batir a las montoneras que allí operaban; disgustado, impuso un despiadado terrorismo" (Roel, 1971, p. 122).

La Serna en consecuencia, al recibir tan negativa noticia, decidió realizar una campaña de mayor envergadura y aniquilamiento, así lo hace notar entre líneas el propio virrey en su manifestación del 20 de marzo de 1821:

Se dirige el General Ricafort con su división desde Huancavelica al punto de la Oroya, tratando, a su paso por Tarma y Jauja, de restablecer el orden, reponer las autoridades y dar tono al partido español sofocado por la osadía de los revolucionarios (...). En el citado punto de la Oroya debe incorporársele el coronel Valdés con su división, (...) el que en su tránsito por la provincia de Huarochirí procurará arrojar las partidas que hasta ahora la tienen sublevada (como se citó en Comisión Nacional de Sesquicentenario de la independencia del Perú, 1972a, p. 73)

La misión de Ricafort era entonces clara, arrasar con los rebeldes de la sierra central, mientras que Valdés haría lo propio con los pueblos de Huarochirí y Yauyos, "atendida la abierta insurrección de los 
partidos de Huarochirí y de Yauyos (...) dispuso el virrey que el coronel Valdés, jefe del Estado Mayor, saliera (...) [para acabar con] las demasías de los indios alzados" (García Camba, 1846, p. 382). Una vez logrado esto, ambos generales tenían por orden dirigirse a la capital para unir fuerzas en una ciudad ya sumergida en el pánico total.

Inmediatamente los huarochiranos y vecinos se alistaron nuevamente para defender sus zonas, los mandos militares patriotas, gracias a las correrías de los espías, estaban al tanto de los movimientos del enemigo, ordenando y preparando rápidamente sus partidas para hacerles frente como menciona Otero: "aviso al Comandante Villar los movimientos y fuerza del enemigo, para que cruce a las quebradas de San Mateo y Huarochirí, a efecto de cortar los caminos de Lima y que no le sea fácil su repliegue al enemigo" (como se citó en la Nueva Colección Documental de Independencia del Perú, 2018a, p. 507). Según los documentos de la época, era de suma importancia menguar a las tropas de Valdez en San Mateo, puesto que, si este lograba unirse con Ricafort sin mayores sobresaltos, Jauja estaría destinada a perderse inevitablemente.

El primer enfrentamiento entre realistas $y$ huarochiranos se dio en los alrededores del pueblo de Sisicaya, donde los lugareños habían cortado los caminos en tres puntos, asimismo, intentaron destruir los puentes pero fueron finalmente descubiertos, por lo que abortaron la misión. El mismo poblado de Sisicaya había sido abandonada, no dejando nada para que el enemigo pueda abastecerse, siendo la misma acción aplicada en Espíritu Santo y Langa, en donde "las fuerzas de Valdez buscaron víveres y forrajes por todas partes, pero no fueron habidos, pues habían sido escondidos" (Rosas, 1995, p. 119). No obstante, si bien los pueblos fueron abandonados, no lo fue así sus alturas, desde donde se posicionaron los guerrilleros para realizar los ataques:

Desde las aturas de Langa continuaron los ataques contra los españoles, mediante la modalidad de las galgas y también con algunos fusiles, en esta localidad, Valdés se enteró que el patriota Pablo Jeremíaz, a la cabeza de una numerosa guerrilla había pasado al pueblo de Huarochirí, con el ganado recogido en toda la quebrada (Rosas, 1995, p. 120).

Las acciones de los valerosos guerrilleros no quedaron en este punto, puesto que persiguieron a los realistas hasta el distrito que lleva por nombre el mismo de la provincia, obstaculizando los caminos para complicar aún más la misión hispana, así, "la caballería realista tuvo que pasar por unos desfiladeros, y también tuvieron que sortear la crecida del río, y soportar lluvias torrenciales" (Rosas, 1995, p. 120). Valdés, desde luego, enfurecido por los ataques y tácticas de tierra arrasada empleada por los pobladores, decidió al llegar al distrito de Huarochirí, incendiar gran cantidad de ranchos de los indígenas.

Con lo presentado, Valdés y sus tropas a duras penas lograron reunirse con las fuerzas de Ricafort en la banda occidental del río grande de Jauja, no obstante, esto no fue impedimento para que ambos generales implantaran cruel terrorismo por las zonas donde transitaban. Así, para finales de abril de 1821, y sin mayores éxitos para éstos, decidieron retornar a Lima. Para su retorno los coloniales decidieron dividir sus fuerzas en dos partes, la primera de Ricafort marcharía sobre Canta, mientras que la Valdés haría lo propio por Huarochirí, éste último, con la reciente experiencia adquirida en dicho territorio creía tener controlada la situación para un tranquilo retorno, sin embargo, las incansables guerrillas de la provincia nuevamente le dieron pelea en las distintas zonas de su localidad, siendo tal el rigor del ataque, que los realistas se vieron obligados a atrincherarse en San Mateo, inmóviles a la espera de ayuda que desesperadamente habían solicitado a La Serna, así pues, partieron desde Lima en su auxilio el general Rodil.

Rápidamente los guerrilleros se enteraron de la ayuda desde la capital, por lo que decidieron marchar hasta Chacrasana y Huampaní para impedir que se reúnan los bandos realistas en la provincia, de igual manera, las tácticas guerrilleras dieron sus frutos, logrando mermar considerablemente las fuerzas enemigas, aunque García Camba (1846) narra todo lo contrario afirmando que Rodil "alcanzó y batió en Chacasana el 18 de mayo a la facción de Santa Olaya, causándole bastante pérdida, y tomándole 24 fusiles y carabinas, una carga de cartuchos, y algunos prisioneros a costa de 12 hombres muertos y heridos" (p. 594).

Lo cierto es que las fuerzas de Rodil y Valdés, indudablemente diezmados, finalmente se reunieron y emprendieron marcha hacia la capital, habiendo perdido sin duda mucho en el camino, hombres, armamentos y los valiosos recursos para la subsistencia capitalina, convirtiéndose así esta incursión hispana, en un completo desastre para sus Revista de Ciencias Sociales Aplicadas Waynarroque| pág. 63 
intereses, su misión de acabar y sofocar todo intento emancipador de los indios no hizo más que avivar la llama indígena, convirtiendo sus campos en tierras fértiles de revolución.

\section{Segunda campaña de Arenales y el freno de San Martín}

La segunda campaña de Arenales consistió básicamente en la pertinaz persecución de éste a las fuerzas de Carratalá, quien en su huida había dejado a disposición patriota las tierras del centro peruano como Jauja, Huancayo y parte de Ayacucho, lo cuales fueron tomados rápidamente por el ejército libertador. Sin embargo, debemos tener en cuenta que parecía ser que la sierra no estaba ligada a las actividades político-administrativas de San Martín, puesto que mientras Arenales se batía y ajustaba detalles para acabar con las fuerzas de Carratalá en el centro, el bonaerense y La Serna, en un nuevo intento de negociaciones dieron inicio a la conferencia de Punchauca, y con ello, un nuevo periodo armisticio. No obstante, no enterado aún Arenales del inicio de estas negociaciones, puso en marcha su plan de acabar con las fuerzas de Carratalá, la cual consistía en asegurar su retaguardia, esto quiere decir, controlar plenamente Huarochirí, crucial si se quería evitar ataques desde la capital:

La sublevación de Guarochirí, debía apoyar los esfuerzos por esta parte. Así pues, la comunicación con Lima (...) quedaba ya absolutamente cortada, ó cuando menos, peligrosa, lo que hacía tanto más difícil la posisción de los gobernantes realistas en estas provincias (José Arenales, 1822, p. 40).

El plan de Arenales había dado resultados positivos, luego de un pequeño enfrentamiento los patriotas habían logrado capturar a 120 soldados realistas entre los que se encontraba el mismísimo Carratalá, no obstante, en un golpe de revés, el general argentino recibió carta donde se le informaba sobre la conferencia de Punchauca y el inicio del armisticio, por lo que se puede decir que la política de San Martín, de entendimiento y negociaciones con los hispanos, se había convertido en una constante traba para acabar con las fuerzas peninsulares, Arenales, su ejército y las guerrillas andinas, habían sido frenados de pleno, no quedándoles más remedio que liberar a los capturados, quienes emprendieron su marcha hacia Huamanga donde tranquilamente pudieron rearmarse.

pág. 64 Waynarroque Revista de Ciencias Sociales Aplicadas
Aquel mandato de San Martín a favor de los coloniales no quedaría solo en la liberación del enemigo, un complaciente libertador nuevamente, y para calmar el pánico de la aristocracia limeña, ordenó a los naturales abstenerse de avanzar hacia la capital, advirtiendo además que se castigaría a todo aquel que intentase acercarse a la ciudad de los reyes. Del lado colonial se temía que los indígenas llegasen a Lima y cometiesen todo tipo de desmanes contra sus bienes, y claro, la protección de la propiedad privada se había convertido en una misión casi sagrada para el apacible bonaerense. En contraparte, podemos decir que Monteagudo no iba en la misma línea que su líder, puesto que "impuso una dura política antiespañola [viendo] en los españoles un peligro potencial porque podían generar una corriente de opinión contraria al protectorado [siendo por ello que] cualquier sospecha dio lugar a destierros, prisiones y fusilamientos" (Rojas, 2018, p. 49).

Más cuestionable aún, es para algunos historiadores, el hecho de que San Martín, luego de la conferencia de Punchauca, y a sabiendas de la retirada hispana hacia la sierra, haya dejado a poblaciones enteras a su suerte, ordenando que el propio Arenales retorne a la ciudad limeña quedando sin protección alguna los indígenas. Los coloniales tenían el panorama claro, hacinados en Lima no ganarían la guerra, había que marcharse hacia el valle del Mantaro, punto clave para sostener una guerra tan prolongada como la que se avecinaba, divididos en dos escuadras, uno comandada por Canterac y la otra por La Serna, se encaminaron por rutas distintas para dividir también a las fuerzas patriotas, siendo el virrey, quien planifique su movimiento por Huarochirí, pasando así los hispanos de sitiados a sitiadores.

No obstante, poco antes de emprender su ruta hacia la sierra, La Serna lanzó una proclama amenazante contra las partidas guerrilleras, esto con el objetivo de frenar los ataques indígenas en su avanzada, algo que, por supuesto quedó en papel para las partidas huarochiranas, quienes no dudaron en enfrentarse a la máxima autoridad hispana. Lo siguiente, es un extracto de la mencionada proclama del virrey:

Habeís abandonado vuestras sementeras: vuestro ganado a desaparecido y andáis herrantes por las punas y quebradas. Volved a vuestras casas, sembrad vuestros campos; recoged vuestras reses, y descuidad por vuestra paz que yo respondo por ella. Deponed todo temor por vuestros desaciertos pasados que os 
los perdono; porque os amo de corazón (...) suministrad los víveres y demás auxilios a mis tropas, y todo se os pagará. Lo contrario será un crimen grave que me obligará a permitir a mis tropas que busquen por si las susbsistencias que reuéis suministrarles (...) Indio no seáis víctima del engaño, y abrazad el saludable consejo que os anticipo; no os desprecieís mis promesas, que por experiencia sabeís que cumplo; pero temed, si lo despresiásis porque no en valde he movido todas mis fuerzas. Quiera Dios que la indulgencia y la suavidad produzca el efecto que me prometo; pues de lo contrario obrará mi ejército, cuyo valor es bastante conocido. (Roel, 1971, pp.137-138).

Los indígenas no eran el único problema que se le presentaba a La Serna, sino también las tropas del general Arenales, quienes luego de liberar a Carratalá se encontraban de regreso a Lima, por lo que tenía que buscar eludir a tamaña e invencible fuerza patriota. Mientras tanto, los pobladores huarochiranos conociendo el inminente arribo de los realistas por su zona, quitaron todo tipo de subsistencia que pudiera beneficiar al enemigo, sin embrago, estos preparativos no sirvieron de mucho debido a que La Serna no pasó finalmente por la provincia, no obstante, las guerrilleros huarochiranos sí tuvieron acción, puesto que Arenales, conociendo del cambio de ruta hispana por Yauyos, envío rápidamente a estas guerrillas hacia la zona en cuestión, así lo hace saber Leguía $(1972$, t. 3):

La oportuna emersión de las guerrillas, empujadas por Arenales desde las quebradas de Huarochirí sobre las de Yauyos, a que siguieron formidables levantamientos de indios, el asendereado virrey hubo de tantear y efectuar su paso por la cordillera. entregado a una verdadero viacrucis (p. 387).

El miedo entonces se apoderó de las tropas de La Serna, experimentando la valentía y los males que causaban los guerrilleros, se reunieron a duras penas con las fuerzas de Carratalá. Por su parte Arenales, conociendo las penurias del enemigo, escribió inmediatamente a San Marín para que éste de rápidas instrucciones a la espera de acabar con los peninsulares de manera contundente, para lo cual, solo le hacía falta refuerzos de la capital:

Resulta, en primer lugar, serme absolutamente necesario abandonar la sierra o decidirme a batir a aquellas fuerzas. Ya se deja ver que La
Serna después de haber logrado la reunión con los que venían del sur con Carratalá, debe venir con su masa presisamente a ocupar estos puntos y si no se embaraza esta concentración, las consecuencias son muy claras. Evacuar la sierra por cualquier parte que haya de tener que atravesar la cordillera, trae el preciso resultado de perder la opinión, perder la caballería, estropear las tropas, perder 1500 reclutas, todos los recursos y por último, esta división. Sabe Dios cuánto podría volver a ponerse en estado de expedicionar nuevamente sobre la sierra. Abandonada la capital por los enemigos, ya no se nececita fuerza para tomarla y poseerla, pues ella misma pediría protección, y para su guarnición basta solamente un cuerpo (...) y que toda lo demás debía venir a componer una masa fuerte en este país precaucionar el cambio del teatro de la guerra mediado por los enemigos; De lo contrario la guerra se va a dilatar mucho por un orden regular y el resultado se pone en duda: Así es que por todas las oportunas razones parece que en fuerza de los intereses del país y el honor de esta división y de todo el ejército debo decidirme a dar el golpe que parece más probable su éxito, o menos aventurado (...) Pero para eso es indispensable y de urgente necesidad, que toda la fuerza de que V.E. pueda disponer en concepto de necesitarse muy poca en Lima la haga venir sin pérdida (Roel, 1971, pp. 147-148).

Los documentos demuestran a un Arenales confiado en que el libertador secundase sus aspiraciones, sin embargo, no había previsto lo obstinado que se encontraba este último con la política monárquica, la cual se basaba casi de manera obligatoria, en llegar a un entendimiento con los hispanos. Lorente (1876), es muy claro al respecto: "al ocupar a Lima, todo se olvidó (...) las consideraciones debidas al pueblo peruano, las necesidades de la guerra y hasta el nombre de libertadores, pensando ante todo en no crear obstáculos á los proyectos monárquicos" (p. 4). Así, mientras que en la sierra todo estaba preparado para una batalla decisiva, desde la capital Arenales será ordenado, muy a su pesar, como lo manifiesta, a retornar junto a sus tropas a Lima, sin realizar ningún tipo de ataque, obligándolo a dejar todo aquello por lo que se había preparado, dejando además al indígena en total desamparo:

No puedo significar a ud. Cuánto siento este acontecimiento, por las consecuencias que Revista de Ciencias Sociales Aplicadas W Wynarroque pág. 65 
percisamente vamos a tocar, muy a nuestra costa, y de los sacrificios del país. Disponedme Ud. Que le hable con franqueza; no se han oído las observaciones tan obvias y convenientes que, con demasiada repetición he significado. ¿Qué ganará nuestro ejército al entrar a Lima y apestarse y acabar de destruirse cuando sus progresos y grande utilidad podía ya estar convalecido en las inmediaciones de la sierra? ¿Qué suecderá con las tropas de esta división con mil quinientos reclutas, ya istruidos y dsiciplinados: si como según se me presenta el caso forzosamente tienen que hacer una deshonrosa retirada para donde esperan los hospitales con el sepulcro? ¡A señor! ¡Qué doloroso es tener que hablarle a ud. En estos términos! No crea, ni por un solo momento, que estas mis expersiones tengan en modo alguno espíritu de reconvención ni de faltarle el respeto (...) ¿Qué será los habitantes de este territorio tan sumamente comprometidos? (...) lo bueno es que yo estoy cubieerto de mis anteeriores comunicaciones dirigidas a Ud. Y con sus preceptos, que obedezco ciegamente si en mi lenta retirada me encontrase con la fuerza de retaguardia enemiga y Canterac no apura mucho, la batiré, procuraré sostenerme lo que pueda (Roel, 1971, pp. 151-152).

La ruta elegida por Arenales para su frustrada contramarcha hacia la capital será Huarochirí, donde los pobladores le brindaron toda clase de ayuda para que su recorrido sea lo menos amargo posible, aunque como lo vaticinó Arenales, "La división dejó la quebrada de San Mateo, y entró en Lima los primeros días de agosto, con más de mil hombres menos de los que tuvo cuando salió de Jauja" (José Arenales, 1822, p. 136). A esto añadiremos que, San Martín, al dar esta orden, no había tomado en consideración las represalias hispanas contra los pueblos que se habían levantado, en adelante, la sierra central será tomada y saqueada por los realistas, sin nadie a protección de estos más que sus propios guerrilleros.

Pese a todo, lo que se puede sacar como conclusión de la segunda campaña de Arenales es que esta fue exitosa, el general había logrado consolidar el levantamiento indígena, y junto a ello, asfixiar aún más a la capital, teniendo dentro de sus consideraciones a los guerrilleros huarochiranos, de los cuales habló en sus memorias de la siguiente manera:
Los yauyos, tan atrevidos y valientes como sus vecinos los Huarochirí, permanecieron en estado de independencia desde que se sublevaron bajo la protección de la división libertadora (...) en la campaña anterior (de 1820). Desde entonces sostuvieron su posición con tal ardor y coraje, que anularon las repetidas tentativas de los españoles para subyugarlos de nuevo (Álvarez de Arenales, como se citó en Leguía, t. 3, 1972, p. 328).

Claro está que el accionar de las valerosas guerrillas huarochiranas no solo quedó en las memorias de los grandes personajes, sino también fue plasmado en los periódicos de la época, como en el de El pacificador del Perú, donde, por ejemplo, en su publicación del 10 de junio de 1821, resaltaron la entrega de dichas partidas por la causa:

Las partidas de guerrillas han hecho celebre el nombre de la Provincia de Huarochirí, hasta los puntos más vecinos a Lima: sus continuas ventajas obtenidas, sobre los enemigos comprueban, que las armas que pone el entusiasmo en mano de los que defienden la tierra en que nacieron, y que conocen desde que existen, son irresistibles (como se citó en Comisión Nacional de Sesquicentenario de la Independencia del Perú, 1972b, p. 215).

Lo llamativo además para la provincia en este periodo será que, el ahora convertido en protector del Perú, declarará al territorio en mención, el 4 de agosto de 1821 como zona libre:

Estando ya libres de la dominación española la Capital del Perú y demás pueblos situados al Sur de ella hasta la Nazca, he venido en decretar lo que sigue:

I. Los partidos del Cercado de la Capital, Yauyos, Cañete, lea, y el Gobierno de Huarochirí formarán uno de los Departamentos libres del Perú, bajo la denominación de Departamento de la Capital.

2. El Coronel Don José de la Riva Agüero está nombrado Presidente del Departamento de Lima; y deberá tener su residencia en la Capital (como se citó en Comisión Nacional de Sesquicentenario de la Independencia del Perú, 1972c, p. 25).

El rol de la provincia entonces, luego de ser decretada libre, recaería principalmente en suministrar de alimentación a la capital y al ejercicio libertador. No obstante, en la práctica si bien los naturales durante un corto periodo sostendrán enfrentamientos fuera 
de su territorio, no se sentirán para nada libertos de los ataques realistas, la incursión enemiga hacia el centro del Perú no hizo más que ubicarlos en medio de los abusos y saqueos de ambos bandos. Asimismo, no se puede dejar de mencionar que, para este periodo, la figura de Riva Agüero comenzará a cobrar mayor protagonismo para la provincia, enlazando sus primeras comunicaciones con dicho territorio al ser nombrado presidente del departamento, un lazo que se mantendrá hasta 1858, cuando su hijo, José de la Riva-Agüero y Looz Corswaren, asuma el cargo de diputado suplente por la mencionada provincia.

En el plano estratégico Huarochirí sirvió como retaguardia hacia donde podían retirarse las tropas a ponerse a salvo de las persecuciones enemigas en el Mantaro (...) pero, de otro lado, esta calidad de zona libre trajo consigo muchos y muy graves problemas y dificultades a la provincia y sus pueblos. Huarochirí fue casi literalmente saqueada en forma continua $y$ reiterada por las tropas de guerrilleros y del ejército regular (Vergara y Quiróz, 1992, p. 144).

\section{Guerrilleros huarochiranos frente a los destacamentos de Canterac y Loriga}

El virrey La Serna antes de emprender su marcha hacia la sierra, había prometido a sus partidarios quedados y atrincherados en la fortaleza Real Felipe, además de remitirles todo tipo de ayuda apenas se encuentre posicionado en el Valle del Mantaro, retornar a la capital para brindarles absoluta protección, siendo su verdadero interés de regresar, el de la gran cantidad armamento que había dejado en el Callao, vital para sostener la prolongación de la guerra. Para recuperar este poderoso armamento, el virrey envío al general Canterac, quien partirá de Jauja el 25 de agosto de 1821 rumbo a la capital, las guerrillas huarochiranas volverán entonces a cobrar protagonismo en la guerra, organizándose y teniendo como punto de ataque las alturas cerca a Santiago de Tuna, donde los guerrilleros lograron una pequeña pero importante victoria al capturar al coronel español Sócoli quien posteriormente fue a la capital para ser interrogado en busca de saber las verdaderas intenciones de los coloniales:

Desde los cantones del valle de Jauja á Santiago de Tuna, atravesando los andes de oriente a occidente, nada particular ocurrió (...) [pero] cerca de Santiago de Tuna cayó en poder de una partida enemiga el teniente coronel don José García Sócoli, agregado al E.M., y fue fatal este incidente porque pudo San Martín informarse de la fuerza realista, y acaso por este dato resolverse á no abandonar á Lima. En el pueblo de Tuna, dividió Canterac la fuerza en dos columnas (García Camba, 1846, p. 414).

Mientras tanto en la capital, San Martín luego de acentuarse en esta se había mostrado confiado en cuanto a sostener que los realistas no avanzarían hacia la mencionada ciudad, ocupándose por tanto de asuntos políticos antes que, de los militares, esto a pesar de mantenerse al tanto sobre los movimientos de Canterac. Para San Martín, el movimiento del general realista no tenía más objetivo que recolectar alimentos, por lo que no se preocupó en reforzar la reciente ciudad tomada por los suyos, mucho menos, en hacerle caso a los primeros llamados de alerta por parte de los huarochiranos.

Lo que decidió el libertador, por el contrario, fue lanzar una proclama que, contraria a sus acciones, prometía a los ciudadanos un pronto triunfo a manos de su ejército, pidiendo a la plebe nada más que su tranquilidad, es decir que no realicen ningún tipo de ataque contra los enemigos. El anuncio claramente se hizo con la intención de frenar a los indígenas que habían tomado plena autonomía en su lucha, y donde, además, las enardecidas almas buscaban desesperadamente armamentos para hacerle frente a Canterac, este que, para su marcha hacia Lima, y para no perder más hombres, dividió a los suyos en dos, siendo él junto a Valdés, quienes continúen su marcha por la provincia, sin alimentos ni guías, y con constantes ataques, la suerte no cambió para los defensores del rey:

Canterac marchaba a la vanguardia de sus unidades mientras Valdés cubría su retaguardia; marchaban de día por un camino para cambiarlo inmediatamente por la noche, pensando así despistar a los montoneros que los hostigaban (...). El hecho es que los campesinos peruanos eran tan contrarios al enemigo, que Canterac no había encontrado un solo guía que estuviera dispuesto a orientarlo, por lo que, en su desplazamiento por la quebrada de San Mateo se desvió más al sur, internándose por la peligrosísima quebrada de Espíritu Santo (Roel, 1971, p. 160).

Lo narrado por Roel demuestra a una provincia Revista de Ciencias Sociales Aplicadas Waynarroque| pág. 67 
plenamente insurgente, que obligaba al enemigo a tomar las medidas más extremas por salvar sus vidas, así, una mejor opción habría sido tal vez el no dividir sus líneas y atacar con toda su superioridad militar a los lugareños, teniendo en cuenta que dicha división le pudo costar a Canterac la pérdida de todos sus soldados al extraviarse por lugares inhóspitos:

Allí se perdieron mulas y caballos con la mayor parte de las maletas de gurupa. Allí hubo piernas, brazos, cabezas y cuerpos estropeados, porque los hombres y las bestias rodaban á la par de precipicio en precipicio; allí hubo muchos que recurrieron á sus propias orinas para mitigar su mortal sed (...) allí varios bravos desesperados se tendían en el suelo como resignados con su fin (...) uno de los que se hallaba a borde de este triste extremo era el coronel D. Gerónimo Valdés, jefe del E.M. que cubría la retaguardia: fatigado por el contínuo afan de animar a la tropa, despues de haber apelado á su orina, á las cortezas de los áridos arbustos y aun á ponerse plomo en la boca para mitigar algo la sed que lo consumia, rendido y falto de fuerzas se acostó al fin en el suelo al lado de una gran peña, donde le acompañaban algunos leales oficiales y soldados, y alli les alcanzaren primero el descubrimiento del agua y poco despues algunas cantimploras (García Camba, 1846, pp. 415-416).

Después de las tantas contramarchas sufridas, las tropas de Canterac Ilegaron a Cieneguilla en condiciones verdaderamente calamitosas, los soldados nuevamente habían caído en desgracia tras su largo trajinar por la sierra huarochirana, su geografía, y sobre todo, la acción de sus guerrilleros, había surtido las mejores ventajas para que San Martín acabe fácilmente con una considerable fuerza realista, así lo hace saber el propio García Camba (1846) en sus memorias:

Si los enemigos hubieran podido saber con oportunidad el estado en que nuestra infantería bajaba á la quebrada del Espíritu-Santo, con algunas compañías la hubiesen rendido facilmente toda; y este riesgo y las demás desgracias y molestias indicadas eran una concecuencia natural de la necesidad de tener que marchar sin guias prácticos del terreno, porque como el país estaba insurreccionado no se hallaba en los pueblos un solo habitante ( $p$ 416).
Las guerrillas entonces habían cumplido en gran parte con su propósito de diezmar a los coloniales, esperando nada más que San Martín pudiera hacer su parte, no obstante, en un nuevo acto de complacencia, el libertador dejó que los realistas se recuperasen y que, sin mayor hostigamiento, marchasen sobre La Molina. Francisco Javier Mariátegui (1869), por su parte, testigo presencial de los hechos, mostró cuán opuesto que se encontraban los limeños con la conducta del libertador, esto al referir lo siguiente: "El pueblo respondía con el solemne juramento de antes morir que ser esclavos" (p. 83), mostrando de manera contundente que la población se encontraba dispuesta a enfrentarse a las fuerzas de Canterac y de dejar la vida si fuera posible por la libertad. El historiador Virgilio Roel (1971) también hace énfasis en este mismo punto, al afirmar que, "en contraste con la pasividad de San Martín, la población corriente de Lima se movilizó con entusiasmo y resolución. Todos pedían armas" ( $p$. 161).

Finalmente quedaba demostrado que la plebe no tenía voz en el levantamiento criollo, puesto que los realistas entraron en plena tranquilidad a la fortaleza del Callao, no obstante, estos no esperaron encontrase con un escenario tan devastador como con el que visaron, donde casi no había alimentos y cundía la anarquía por el control de los pocos recursos, por lo que, la llegada de Canterac y los suyos, en lugar de traer esperanzas, trajo consigo peores males aún, sus tropas igual de hambrientas y heridas no serían las que llevasen el alimento a la fortaleza, sino por el contrario, los que la pidieran.

No cabe duda entonces que el plan español había fracasado, sin poder siquiera retirar el armamento, no les quedó otra opción que volver hacia la sierra, siendo nuevamente, al estar desgastados, blanco fácil para los patriotas. Sin embargo, nada habría de cambiar en el pensamiento del Protector, puesto que nuevamente ordenó a su ejército esperar el ataque mientras los hispanos avanzaban rápidamente hacia su refugio, siendo de manera tardía que el general ordene perseguir al enemigo mas no de entablar un enfrentamiento directo con éstos, el encargado de cumplir dicha misión el General Las Heras, a quien posteriormente, justo cuando los hispanos comenzaban a caer bajo sus armas, se le ordenó replegarse. 
Al posicionarnos ya a finales de 1821, San Martín comenzaba a perder credibilidad ante la opinión pública, "un ejército como el Libertador, numeroso y entregado a la ociosidad, produjo la desmoralización de él y descrédito de San Martin, que parecía [además], aletargado en la barbarie ejercida por su ministro Monteagudo" (Bilbao, 1853, p. 28). Así, para noviembre de 1821, lo máximo que hizo por los guerrilleros huarochiranos y sus vecinos fue condecorarlos con decretos inocuos y ciegos de toda la aspiración emancipadora:

La constancia y señalado patriotismo que han acreditado durante la campaña los peruanos del departamento de Tarma, y provincias de Cangallo, Huarochirí, Canta, Yauli y Yauyos, lo hacen acreedores a la estimación pública y del gobierno. El enemigo que ha conocido el valor de sus esfuerzos ha desplegado contra ellos, cuando ha podido, un odio que los honra, en premio a sus virtuosos sentimientos, declaro:

1.- Los peruanos de las tres provincias mencionados desde la edad de 15 años hasta los 50, llevarán un escudo elíptico en el brazo izquierdo de paño encarnado con esta inscripción bordada de hilo de plata:

A los constantes patriotas de Huarochirí, variándose el nombre de la provincia en los términos que se ha indicado (Vergara y Quiróz, 1992, p. 142).

Del lado de las guerrillas huarochiranas, lo que se puede decir antes de la proclamación de su independencia es que en seguida del recorrido de Canterac y sus fuerzas por sus tierras, otro destacamento realista pasó por la mencionada provincia, esta vez, haciéndose presente en el territorio el General español Loriga al mando de un pequeño contingente, y aunque los guerrilleros no lograron un éxito similar al anterior diezmar considerablemente al enemigo, sus acciones fueron nuevamente reconocidos por estos:

la caballería con el $2^{\circ}$ batallón del primer regimiento que mandaba D. Francisco Narvaez, la artillería, el ganado y los bagages bajaron directamente á la Cieneguilla á las órdenes del Coronel D. Juan Loriga, batiendo y dispersando al paso la montonera ó facción de Huarochirí, que situada en una posición fuerte intentó inutilmente detener la marcha de esta columna, y tuvo de pérdida varios muertos y heridos, un oficial y 26 hombres prisioneros con algunos caballos ensillados (García Camba, 1846, p. 114-115).

\section{Huarochirí después de su independencia}

Después del afianzamiento hispano en el valle del Mantaro, y de la "liberación" de la provincia, Carampoma pasará a ser el nuevo fortín huarochirano, donde por ejemplo se posicionará y remitirá sus órdenes el acaudalado comerciante Paula de Otero. No obstante, es necesario aclarar que, si bien los realistas seguirán incursionando en la provincia, esto ya no se realizará de manera constante, por lo que este pequeño lapso de descanso será aprovechado por los pobladores para declarar la independencia de Huarochirí, contando además con apoyo de la iglesia local, quienes se habían sumado la "causa justa de la revolución", y que inclusive, contribuían monetariamente con el ejército libertador. Lo cierto es que, más que real, la ceremonia representó un acto simbólico y motivante para los lugareños:

Don Camilo Garrido, cura de Santa Eulalia, quien hizo jurar la independencia en dicha localidad, el 30 de septiembre de 1821. Don Domingo Palma, párroco de San Lorenzo de Quinti, quien hizo jurar la independencia en dicho pueblo, el 28 de octubre de 1821. El padre fray Bernardino Negrón, de la doctrina de Carampoma, quien presidió la jura de la independencia en dicha localidad con el padre José Manuel Carrillo, cura de Carampoma, el 12 de diciembre de 1821 (Rosas, 1995, p. 131).

Los escasos ataques realistas no inhibían desde luego a la provincia del temor y de las constantes amenazas de incursión a la zona por parte de los coloniales, más aún conociendo estos que los pueblos huarochiranos contaban con una gran cantidad de alimentos, y que era junto a Yauyos, una de las principales provincias que abastecían al ejército patriota. Existe para este periodo, numerosa documentación certificando las constantes tentativas realistas de atacar Huarochirí, lo que implicaba que las guerrillas estén en constante alerta ante cualquier movimiento enemigo, por ende, alejados de toda vida apacible, preocupados por cualquier incursión devastadora como lo advertía José María Rivera: "Los enemigos (...) van a venir a estos lugares a destrozarnos con mucha furia" (como se citó en Nueva Colección Documental de la Independencia del Perú, 2018b, p. 383).

Producto de la desconfianza de los pobladores, lo que empezó con fuerza en este periodo será las constantes tácticas de guerra conocidas como tierra arrasada, los documentos nos muestran un sin Revista de Ciencias Sociales Aplicadas W Wynarroque| pág. 69 
número de veces en las que los lugareños tuvieron que sacar todo lo que podría servir a los realistas, dejando las tierras desérticas ante cualquier información que llegaba desde la sierra central. La posterior carta es de José María Rivera, la cual, como otras tantas, solicita justamente este trabajo a los indígenas:

he impartido ordenes a los de la Quebrada de Matucana; San Mateo, y demas pueblos de la misma retiren todos sus intereses y alhajas de las iglesias al punto de Santa Ines, y los de la quebrada de Sisicaya al Pueblo de Huaycan, y todos estos que componen la Doctrina de Huarochiri, y San Lorenzo al Pueblo de Olleros, con la expresa orden que (...) se retiren con todos sus intereses hasta esa Corte, para que los enemigos no puedan tomar sus intereses, y proveerse de ganado para su manutencion (como se citó en Nueva Colección Documental de la Independencia del Perú, 2018b, p. 393).

Otro accionar que caracterizará a los guerrilleros de la provincia será su labor de espías y mensajeros, siendo su minuciosidad y rapidez una garantía para Paula de Otero, quien decía no ignorar ningún movimiento de los enemigos gracias a la laboriosa tarea de los mencionados, "los tiranos no harán movimiento que yo lo ignore y si alucinados de su orgullo, hacen movimiento por estas Quebradas sufrirán hostilidades continuas" (como se citó en la Nueva Colección Documental de la Independencia del Perú, 2018b, p. 599). Por lo que Tomás Guido, conociendo la importancia de éstos, decide redoblar sus esfuerzos para que nada le sea ajeno, "es importantísimo se doble la vigilancia para averiguar los movimientos y tomar si es posible un prisionero que instruya con fijeza en todo" (como se citó en la Nueva Colección Documental de la Independencia del Perú, 2018b, p. 402).

Lo que se desprende de lo dicho por el Ministro de Guerra, es que los espías no solo se ocupaban de la vigilancia de los movimientos enemigos, sino que además, en algunas oportunidades realizaban captura de, en su mayoría, análogos espías realistas, quienes eran enviados a la provincia con la misma misión de los patriotas, no obstante, si estos eran apresados se les castigaba "con doscientos azotes", o incluso en algunas oportunidades eran fusilados por órdenes de los gobernadores, aunque claro está que en su mayoría eran remitidos a la capital para su posterior interrogación.

pág. 70 Waynarroque Revista de Ciencias Sociales Aplicadas
El rol que cumplían los espías era crucial, notándose en cada uno de los documentos la importancia con las que eran tomados sus informes por los gobernadores político-militar, gozaban pues de gran credibilidad para Paula de Otero, quien apenas recibía una información de ataque enemigo ordenaba inmediatamente a sus hombres a que ajustasen todo detalle de prevención dictaminando órdenes como la siguiente: "he proyectado sacar de cada pueblo de la Provincia de Huarochirí cinco hombres solteros (...) para reunir algún número de gente y poder cubrir con facilidad todas las avenidas, y poder hostilizar al enemigo" (como se citó en la Nueva Colección Documental de la Independencia del Perú, 2018b, p. 496).

Los espías de la zona se habían convertido en una especie de chasquis realizando sus correrías en postas como se puede notar en esta otra carta de Otero a San Martín: "he mandado espías para tomar más exactas noticias, y he prevenido a los Comandantes de Partidas, que luego que llegue un espía remitan otro en seguida, a fin de no perder momento en saber sus movimientos" (como se citó en la Nueva Colección Documental de la Independencia del Perú, 2018b, p. 496).

Así, para mediados de julio de 1822, gracias a la labor infatigable de los espías se conocía a la perfección el plan realista de incursionar sobre Lima, siendo inmediatamente los guerrilleros de la provincia quienes reciban la orden de Tomás Guido, la misma que consistía en poner "la mayor resistencia posible en los desfiladeros y puntos ventajosos que ella [Huarochirí] ofrece, pero sin exponerse a ser envueltos o destruidos por un compromiso temerario" (como se citó en la Nueva Colección Documental de la Independencia del Perú, 2018b, p. 501). Sobre esto último debemos considerar que el ministro de Guerra tenía claro sobre cómo debían batirse las montoneras:

primero es organizar las partidas, hacer impracticables las principales avenidas [es decir quebradas] en la provincia, asegurar su defensa, y después amargar parcialmente sin comprometerse sino con duplo número de fuerzas, a menos que un desfiladero preciso u otra posición ventajosa supla la falta de disciplina que hay en todas las partidas, por la cual debe siempre evadirse en su empeño en los llanos con el enemigo (Temple, como citó Vergara y Quiróz, 1992, p.137). 
Otros que desempeñaron funciones en busca de tratar de convencer a los guerrilleros para que no se enfrentasen "peligrosamente" a los realistas serían los miembros de la iglesia, quienes recibían tal mandato de los altos mandos militares, y en algunas oportunidades incluso del propio San Martín, como es el caso del cura Pedro Bernuy, quien recibió instrucciones del bonaerense de la siguiente manera: El ejército se prepara para salir muy pronto. Haga usted entender a estos pobres peruanos. Que tengan un poco de paciencia, seguros que saldrán de la opresión en la que se hallan, en todo el presente mes (carta de San Martín, como se citó en Vergara y Quiróz, 1992, p. 138).

Para finalizar, no podemos dejar de mencionar los enfrentamientos que de todas maneras se llevaron a cabo en la provincia, como la del 29 mayo de 1822 en el pueblo de Uco, donde tras media hora de tiroteo, las fuerzas realistas de mil quinientos hombres superaron a las guerrillas huarochiranas donde se encontraba el propio curaca Ninavilca, quien logró escapar resguardándose en el pueblo de Tupicocha, desde donde narró lo ocurrido:

Nos acometieron en número de mil quinientos con quienes tuvimos media hora de tiroteo de suerte que nos vencieron el punto tuvimos que salir dispersos por donde Dios nos ayudase y principalmente la tropa de Vivas que perdió toda su caballada, armas, y gente yo con el favor de Dios escape los cañones, armas, y gente toda completa (como se citó en la Nueva Colección Documental de la Independencia del Perú, 2018b, 402).

Con ello vemos que, a mediados de 1822, nuevamente las fuerzas realistas comenzaron a merodear la provincia en busca de recursos, encargándose de tal misión el propio Canterac, quien con la crueldad que lo caracterizaba, iba arrasando con todo lo que podía destruir a su paso, así por ejemplo "el 30 del propio mes, Canterac mismo destrozó otra guerrilla yaulina (...) y, el día siguiente (31 de mayo), una tercera, de huarochiranos, en las crestas de Viscamachay, del distrito de San Mateo" (como se citó en Nueva Colección Documental de la Independencia del Perú, 2018c, p. 394). Con estos nuevos ataques, las partidas huarochiranas que se habían instalado en las fronteras de su territorio, pasarán a marchar ahora hasta la inmediaciones de Jauja, fuera de sus tierras en busca de sorprender al enemigo y con el firme propósito de no dejar cruzarlos hacia sus pueblos, así lo hace saber el informe de Otero a San Martín, "las Partidas de Prada y Ninavilca están en regular estado y quedan situadas en Pachacha [Jauja], con partidas de los Pueblos que cubren la orilla del Rio" (como se citó en Nueva Colección Documental de la Independencia del Perú, 2018d, p. 279).

Lo que se debe tener en cuenta además es que la marcha de estas partidas implicaba a la vez mayores sacrificios, puesto que como es sabido, las guerrillas no podían bajar en número a la del ejército colonial, por lo que para esta y demás misiones, conforme además iba pasando el tiempo y las muertes comenzaban a diezmar a los suyos, se necesitaba de nuevos grupos de indígenas, los cuales serán reclutados, desde este periodo y en mayor cantidad, en los pueblos de la provincia a órdenes de Paula de Otero como lo hace saber en su carta a San Martín: "voy a colectar mulas con el objeto de sacar de la Provincia de Huarochirí cinco hombres por Pueblo (...) para poner un número considerable de tropa, a fin de cubrir las avenidas" (como se citó en Nueva Colección Documental de la Independencia del Perú, 2018d, p. 280).

Julio y agosto de 1822 se habían transformado en meses de pura actividad para las guerrillas, los constantes informes espías que aseveraban un inminente arribo de los hispanos a sus tierras no dejaban a nadie quieto, menos aún a las aguerridas partidas de Ninavilca, quienes no paraban de moverse mientras las órdenes y contra órdenes se convertían en una constante tratando de encontrar una estrategia unánime para atacar a los defensores del Rey. Sobre el terreno donde se disputaría el enfrentamiento no había discusión, ese era la quebrada de San Mateo, sus claras ventajas ya mencionadas, no dejaba nada a debate, las condiciones proporcionadas por la inhóspita quebrada era resaltada a cada instante, como por Rudecindo Alvarado, quien haría gala de lo mencionado en una de sus cartas a Paula de Otero, recomendándole a éste último que conduzca a los guerrilleros huarochiranos hacia sus ventajosas tierras de San Mateo: "De oficio he dicho a Usted (...) que previniese a esas partidas que lo condujeran por Yauli y San Mateo hasta Lomo Largo donde se halla Fiestas con el Ejercito" (como se citó en la Nueva Colección Documental de la Independencia del Perú, 2018b, p. 603). 
En este mismo tiempo, mientras las guerrillas en Huarochirí y sus alrededores se preparaban para batallar contra los soldados realistas, en la capital se había acrecentado la crisis política durante la partida de San Martín a Guayaquil para entrevistarse con Bolívar. Los influyentes criollos peruanos, como Sánchez Carrión o el mismísimo Torre Tagle, aprovecharon la salida del bonaerense para expulsar al repudiado Monteagudo, reflejándose así, la pérdida de poder por parte del libertador, sus pocos avances militares, sumados a la gran disminución fiscal producto de la prolongada guerra, fueron los principales detonantes para que la aristocracia peruana comenzara a actuar con mayor firmeza, presionando al mismísimo San Martín para que dimita de su cargo.

El protector entonces, desgastado y consiente de las grandes dificultades para que su proyecto monárquico vea la luz, comenzó pues, los preparativos para su retirada del Perú, dejando así, bases para la institucionalización de la patria, convocando para ello a elecciones con la cual se formaría el primer congreso constituyente. Por supuesto, no era de extrañarse que éstas elecciones también estuvieran trabadas, siendo finalmente el 20 de septiembre, día en la que los tan solo 51 diputados elegidos lograran reunirse, abriendo con ello, una nueva etapa en la guerra, pues San Martín, ese mimo día abandonaría el país enrumbándose hacia Chile, no quedándole otra opción al congreso que elegir a una junta gubernativa, la cual estaría presidida por La Mar, quien tomará las riendas del país desde septiembre de 1822 hasta el 27 de febrero de 1823, día en la que Riva Agüero se alce en el poder.

\section{Epílogo}

Podemos decir que la historia independentista de la provincia huarochirana es un suceso casi inédito para el país, esto teniendo en cuenta que hasta el momento no se ha encontrado una bibliografía que ofrezca una visión uniforme y compacta del solo acontecer de la relevante provincia, por lo que en la presente se ha intentado dar mayores alcances de la participación indígena de la zona con la finalidad de lograr todo un proceso de reconstrucción de nuestra historia, una sin olvidar o relegar ningún acontecimiento que, desde luego, nos es útil para formar una historia integral de una patria en construcción. Existe por supuesto, mucho más por investigar al respecto sobre la participación del indígena huarochirano en la emancipación, el accionar de Quispe Ninavilca, la llegada de Marcelino
Carreño a la zona, los acontecimientos durante los gobiernos de Riva Agüero y Simón Bolívar, las colaboraciones forzosas a las que eran sometidos los lugareños, entre otros hechos históricos igual de relevantes convierten el proceso histórico de Huarochirí en una tarea pendiente para la investigación post bicentenario.

Como se ha planteado, la guerra por la independencia durante la estadía de San Martín, no fue más que un proceso alargado por intereses particulares, los mismos que terminaron siendo perjudicial para la provincia huarochirana que cada vez perdía más en hombres y alimentos, por lo que debemos resaltar que no solo los principales acontecimientos de la lucha por la independencia se desarrollaron en las principales ciudades de la costa, centro y sur del país, sino también, en cada uno de los pequeños territorios de nuestra fragmentada República. Hemos visto líneas arriba cómo y con qué sostuvieron sus enfrentamientos los huarochiranos frente a los realistas, no contando con más que sus galgas y con sus aguerridas almas para dar batalla en cualquiera de sus puntos como Tupicocha, Santiago de Tuna, el pequeño pueblo de Uco o en la propia Santa Olaya (actual Santa Eulalia), lugares que no forman parte del redar de la historia oficial, pero que dentro de ellas, sucedieron acontecimientos en demasía relevantes para obtener una rápida victoria por parte de los patriotas.

En consecuencia, así como no podemos ignorar los sucesos históricos de Huarochirí, tampoco podemos hacer lo mismo con el resto de provincias que parecen ser relegadas en la historiografía contemporánea, como por dar un ejemplo, la provincia de Yauli, a la que se le menciona incluso mucho menos que Huarochirí, pero que, sin embargo, si se revisa la documentación sobre el tema, se puede notar un gran movimiento en la zona. Por lo que es hora de ver la microhistoria con mayor énfasis, de verla como una alternativa del proceso de descolonización de nuestra patria, donde se recoja toda historia sin minimizarla, donde seamos conscientes que cada rincón del país luchó por lo que hoy tenemos, y que, a su vez, sigue luchando por una interculturalidad en un país pluricultural.

\section{Referencias}

Anna, T. (2003). La caída del gobierno español en el Perú. Lima, Perú: Instituto de Estudios Peruanos. 
Arenales, J. (1822). Memoria histórica sobre las operaciones e incidencias de la División libertadora a las órdenes del Gen, D. Juan Antonio Álvarez de Arenales, en su segunda campaña á la sierra del Perú en 1821. Buenos Aires.

Barriera, Darío (2002) "Las 'babas' de la microhistoria. Del mundo seguro al universo de lo posible", en Barriera, Darío (Comp.) Ensayos sobre microhistoria. México, Jitanjáfora.

Bilbao, Manuel, Historia del general Salaverry, Lima, Imprenta del Correo, 1853.

Clave, L. M. (2005). Las otras rebeliones: cultura en la génesis de la independencia andina. Nueva Crónica, 2, 189-230.

Colección Nacional del Sesquicentenario de la Independencia del Perú (Ed.) (1972a). Documentación Española. Colección Documental de la Independencia del Perú (t. XXII, vol. 2).

Colección Nacional del Sesquicentenario de la Independencia del Perú (Ed.) (1972b). Los periódicos. Colección Documental de la Independencia del Perú (t. XXIII, vol. 1).

Colección Nacional del Sesquicentenario de la Independencia del Perú (Ed.) (1972c). Obra de Gobierno y Epistolario de San Martín. Colección Documental de la Independencia del Perú (t. XIII, vol. 1).

Dellepiane, C. (1977). Historia militar del Perú. Lima, Perú: Ministerio de Guerra del Perú.

de Vidal, F. (1972). Memoria escrita en 1855, después de la batalla de La Palma. Lima: Comisión Nacional de Sesquicentenario de la Independencia del Perú (Ed.).

García Camba, A. (1846). Memorias para la historia de las armas españolas en el Perú. 2 tomos. Madrid, España: Sociedad Tipográfica de Hortelano y Cía.

Gómez, L. (1999). La iglesia y la emancipación en el Perú, claves interpretativas. En F. Armas Asín (Ed.), La construcción de la iglesia en los andes (siglos XVI-XX) pp. 333-387. Lima,
Grendi, Eduardo (1996) “¿Repensar la microhistoria?”, en Entrepasados, $n^{\circ} 10,131-140$, Buenos Aires.

Huerto, H. (2018). Guerrillas y Montoneras durante la independencia [Vol. 1]. Lima, Perú: Universidad Peruana de Ciencias Aplicadas.

Leguía y Martínez, G. (1972): Historia de la Emancipación del Perú: el Protectorado. [t. III y IV]. Lima, Perú: Comisión Nacional del Sesquicentenario de la Independencia del Perú.

Lorente, S. (1876). Historia del Perú desde la proclamación de la independencia, vol. I: 1821-1827. Lima, Imprenta Calle de Camaná.

Mariátegui, Francisco Javier. Anotaciones a la Historia del Perú independiente de don Mariano PazSoldán. Lima: Imprenta de El Nacional, 1869,

MC. Evoy, C. (2015). De la República imaginada a la República de armas. Lima, Perú: Instituto de Estudios Peruanos.

Méndez, C. (2014). La República plebeya. Huanta y la formación del estado peruano, 1820-1850. Lima, Perú: IEP.

Montoya, G. (2019). La independencia controlada: Guerra, gobierno y revolución en los andes. Lima, Perú: Sequilao editores.

Montoya, G. (2002). La independencia del Perú y el fantasma de la revolución. Lima, Perú: Instituto de Estudios Peruanos.

Nueva Colección Documental de la independencia del Perú. (Ed.) (2018a). Guerrillas y Montoneras durante la Independencia. Colección Documental de la independencia del Perú (vol. I).

Nueva Colección Documental de la independencia del Perú. (Ed.) (2018b). Guerrillas y Montoneras durante la Independencia. Colección Documental de la independencia del Perú (vol. II).

Nueva Colección Documental de la independencia del Perú. (Ed.) (2018c). Guerrillas y Montoneras durante la Independencia. Colección Documental de la independencia del Perú (vol. VI).

Revista de Ciencias Sociales Aplicadas W aynarroque| pág. 73 
Nueva Colección Documental de la independencia del Perú. (Ed.) (2018d). Guerrillas y Montoneras durante la Independencia. Colección Documental de la independencia del Perú (vol. III).

Pasquali, p. (2004). San Martín, la fuerza de la misión y la soledad de la guerra. Buenos Aires, Argentina: Emecé.

Paz-Soldán, M. (1868). Historia del Perú independiente, primer periodo 1819-1822. Lima, Perú. Alfonso Lemale.

Roel, V. (1971). Los libertadores. Lima, Perú: Editorial Gráfica Labor.

Rojas, R. (2018). Cómo matar a un presidente: los asesinatos de Bernardo de Monteagudo, Manuel Pardo y Luis M. Sánchez Cerro. Lima, Perú: Instituto de Estudios Peruanos.

Rosas Cuadros, E. (1995) La provincia de Huarochirí en la historia: coloniaje e independencia. Lima, Perú: [editor no identificado].

Sotelo Hildebrando, R. (1942) Las insurrecciones y levantamientos en Huarochirí y sus factores determinantes. Lima, Perú: La Prensa.

Vergara, A. y Quiróz F. (1992) Los curacas de Huarochirí y su preferencia en las guerrillas de la independencia y los primeros años de la República (1750 - 1830). En Municipalidad distrital de Santa Eulalia (Cord.), Huarochirí, ocho mil años de historia T. 2, (pp. 95 - 154). Lima, Perú: Editorial e Imprenta Desa. 